\title{
A regional epidemiology of India's "NCD's risk factors" focusing particularly on Maharashtra: A call for "Health promotion" once again
}

\section{Balu Natha Mote}

Center of Public Health, Masters of Public Health in Social Epidemiology, TISS, Mumbai, Maharashtra, India

Address for the Correspondence:

Dr. Balu Natha Mote,

Masters of Public Health in

Social Epidemiology, TISS,

Mumbai, Maharashtra, India

E-mail: mote.balu84@gmail.com

\section{Access this article online}

Website: www.ijmedph.org

DOI: $10.4103 / 2230-8598.179756$

Quick response code:
Introduction: Noncommunicable diseases (NCDs) are the leading causes of death globally; almost two-thirds of all deaths are due to NCDs. The International Diabetes Federation noted that India's prevalence of diabetes among 20-79-year-old is $9.09 \%$. India has 65 million of diabetes cases which will rise to 109 million by 2035, only second to China which has 98 million diabetics that will increase to about 142.7 million by 2035 . Today's investment in rupees on NCDs will save our millions lives and rupees in future attributed to NCDs. Ministry of health and family welfare survey of 2012-2013 districts levels survey-4 involved the variables of NCD's risk factors. Materials and Methods: The present study analyzed the available data of NCD's risk factors (17 states available data and district wise data of Maharashtra), particularly blood sugar and hypertension for these states, which were available on the websites of ministry. Results: Prevalence of "risk factors" of NCDs, particularly "raised blood sugar (hyperglycemia)" and "raised blood pressure (hypertension)" found more in North Indian people followed by South Indian and North-East people. In case of focused state of Maharashtra, percentages of people affected with hyperglycemia found in rest of Maharashtra (ROM) followed by Marathwada whereas raised hypertension were found more in ROM followed by Vidarbha region indicating future mortality and morbidity associated with NCDs. Conclusion: "Strong and separate health education program" is needed at central level for the intervention and prevention of "risk of future NCD's risk factors" to tackle the upcoming burden and cost associated with NCDs.

Key words: Blood pressure, blood sugar, hypertension, risk factors and noncommunicable diseases

\section{INTRODUCTION}

Noncommunicable diseases (NCDs) are the leading causes of death globally, almost two-thirds of all deaths are due to NCDs. NCDs, especially cardiovascular disease, diabetes mellitus, and stroke, have emerged as a major public health problem in India. The International Diabetes Federation noted that India's prevalence of diabetes among 20-79-year-old is $9.09 \%$. India has 65 million of diabetes cases which will rise to 109 million by 2035, only second to China which has 98 million diabetics that will increase to about 142.7 million by $2035 .{ }^{[1]}$ Almost half of the people with diabetes in India are undiagnosed. Studies undertaken from 2000 onward show regional differences in the prevalence ranging from $11-19 \%$ for urban areas and 3-9\% for rural areas. WHO noted that hypertension is the leading cause of half of the deaths leading to stroke and heart diseases. ${ }^{[2]}$ One out of ten people

This is an open access article distributed under the terms of the Creative Commons AttributionNonCommercial-ShareAlike 3.0 License, which allows others to remix, tweak, and build upon the work non-commercially, as long as the author is credited and the new creations are licensed under the identical terms.

For reprints contact: reprints@medknow.com

How to cite this article: Mote BN. A regional epidemiology of India's "NCD's risk factors" focusing particularly on Maharashtra: A call for "Health promotion" once again. Int J Med Public Health 2016;6:26-30. 
above the age of 18 years has increased blood sugar whereas every forth individual above the age of 18 years has raised blood pressure (BP) (hypertension), indicating future burden and risk of deaths associated with NCDs. ${ }^{[3]}$

NCDs have common risk factors such as tobacco-use, unhealthy diet, physical inactivity, raised BP, raised blood sugar, and excess adiposity. State and districts level's survey (DLHS-4: Year 2012-2013) done by the Ministry of health and family welfare 2012-2013 for the $1^{\text {st }}$ time collected and included data of blood sugar and BP as risk factors of NCDs. This study will show the brief regional state-wise disparities of the risk factors of NCDs at India level and special focus on district level disparities of risk factors (blood sugar and BP) of Maharashtra state.

\section{AIM AND OBJECTIVE OF STUDY}

- To study the region-wise state level NCD's risk factors focusing on blood sugar and BP

- To study the district level NCD's risk factors (blood sugar and BP) focusing on Maharashtra.

\section{MATERIALS AND METHODS}

Secondary data available from the DLHS-4 year 2012-2013 survey were analyzed for the available state and special focus on district level analysis of Maharashtra.

\section{Definition of risk factors}

\section{High blood sugar}

- High blood sugar - fasting blood sugar $>140 \mathrm{mg} / \mathrm{dl}$

- Very high blood sugar level - fasting blood sugar $>160 \mathrm{mg} / \mathrm{dl}$.

\section{High blood pressure}

- High BP-systolic and diastolic BP $>140 / 90 \mathrm{~mm}$ of $\mathrm{Hg}$

- Moderately high BP - systolic and diastolic BP >160/100 mm of $\mathrm{Hg}$

- Very high BP-systolic and diastolic BP >180/110 mm of Hg.

\section{Selection of states in India and districts in Maharashtra}

\section{Selection of states}

17 states data available analyzed and states were divided into three regions, namely Northern states $(n=4)$, North-East $(\mathrm{NE})$ states $(n=7)$ and Southern states $(n=6)$ [Table 1].

\section{Selection of districts in Maharashtra}

All 34 district's data on blood sugar and BP were analyzed and districts were divided into 3 regions based on administration division, namely rest of Maharashtra (RoM), Vidarbha, and Marathwada [Table 2].

\section{Analysis}

Descriptive statistical analysis and graphics of boxplot used for the better exploration of finding.

\section{RESULTS}

Results are divided into two parts:

1. Region-wise state level analysis of India [Table 3, Figures 1 and 2].

2. District level analysis of Maharashtra [Table 4, Figures 3 and 4].

\section{Region-wise blood sugar analysis of India}

We can conclude from Table 3 and Figure 1 that percentages of population of blood sugar $>140 \mathrm{~g}$ are more in northern region

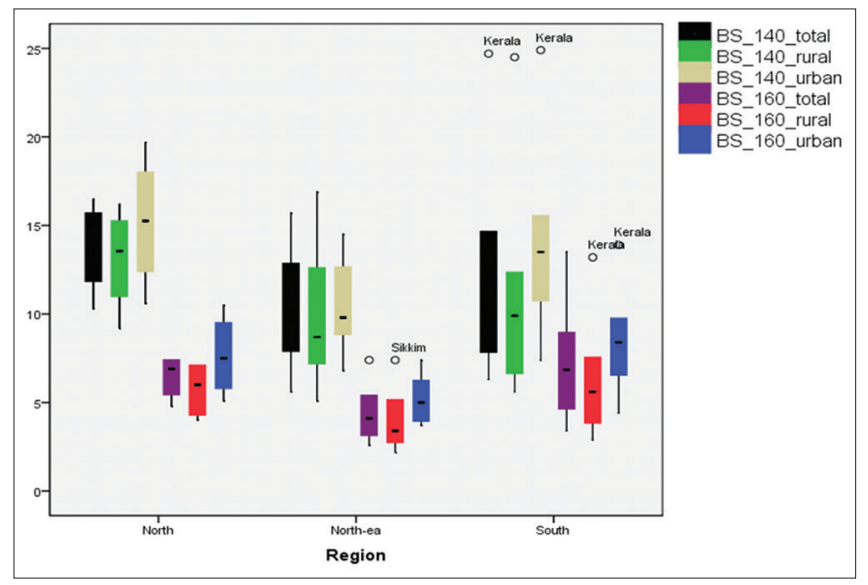

Figure 1: Region-wise state level distribution of Blood sugar of India Note: X-axis shows the Region wise distribution of Blood Sugar; Y-axis shows the \% of population of respective states within region. BS_140_ total/rural/urban means Blood sugar $>140 \mathrm{mg} / \mathrm{dl}$ for the total/rural/ urban area; BS_160_total/rural /urban means Blood sugar>160mg/dl for the total/rural /urban area

Table 1: Region-wise division of 17 states of India

\begin{tabular}{lll}
\hline Northern $(n=4)$ & North-East $(n=7)$ & Southern $(n=6)$ \\
\hline Chandigarh & Arunachal Pradesh & Andhra Pradesh \\
Haryana & Manipur & Karnataka \\
Himachal Pradesh & Meghalaya & Kerala \\
Punjab & Mizoram & Pondicherry \\
& Nagaland & Tamilnadu \\
& Sikkim & Telangana \\
& Tripura & \\
\hline
\end{tabular}

\begin{tabular}{lll}
\multicolumn{3}{l}{ Table 2: Region-wise division of Districts } \\
\hline Marathwada & Rest of Maharashtra (RoM) & Vidarbha \\
\hline Aurangabad & Ahamadnagar & Akola \\
Beed & Mumbai & Amravati \\
Hingloli & Dhule & Bhandara \\
Jalna & Jalgaon & Buldana \\
Latur & Kolhapur & Chandrapur \\
Nanded & Nashik & Gadchiroli \\
Osmanabad & Pune & Gondiya \\
Parbhani & Raigad & Nagpur \\
& Ratnagiri & Wardha \\
& Sangli & Yevatmal \\
& Satara & Washim \\
& Solapur & \\
& Sindu durga & \\
& Thane & \\
& Nadurbar & \\
\hline
\end{tabular}




\begin{tabular}{|c|c|c|c|}
\hline Characteristics & $\begin{array}{c}\text { North states } \\
\text { Mean \% ( } \pm S D)\end{array}$ & $\begin{array}{c}\text { North-East states } \\
\text { Mean \% ( } \pm \text { SD) }\end{array}$ & $\begin{array}{c}\text { South states } \\
\text { Mean \% ( } \pm S D)\end{array}$ \\
\hline \multicolumn{4}{|l|}{ Analysis of blood sugar level } \\
\hline Blood sugar $>140$ & $13.77(2.56)$ & $10.21(3.50)$ & $12.73(6.5)$ \\
\hline Blood sugar >140 in rural area & $13.12(2.89)$ & $10.04(4.01)$ & $11.48(6.8)$ \\
\hline Blood sugar $>140$ in urban area & $15.20(3.7)$ & $10.58(2.5)$ & $14.26(5.92)$ \\
\hline Blood sugar $>160$ & $6.42(1.09)$ & $4.45(1.6)$ & $7.36(3.5)$ \\
\hline Blood sugar $>160$ in rural area & $5.7(1.32)$ & $4.11(1.74)$ & $6.45(3.66)$ \\
\hline Blood sugar $>160$ in urban area & $7.65(2.22)$ & $5.21(1.34)$ & $8.5(3.18)$ \\
\hline \multicolumn{4}{|l|}{ Analysis of blood pressure (high) } \\
\hline Blood pressure $>140 / 90 \mathrm{~mm}$ of $\mathrm{Hg}$ & $31.12(4.64)$ & $25.55(7.56)$ & $24.18(5.22)$ \\
\hline Blood pressure $>140 / 90 \mathrm{~mm}$ of $\mathrm{Hg}$ in rural area & $30.30(5.16)$ & $24.62(8.28)$ & $23.81(6.4)$ \\
\hline Blood pressure $>140 / 90 \mathrm{~mm}$ of $\mathrm{Hg}$ in urban area & $32.47(4.33)$ & $27.48(6.55)$ & $24.61(4.98)$ \\
\hline \multicolumn{4}{|l|}{ Analysis of blood pressure (moderately high) } \\
\hline Blood pressure $>160 / 100 \mathrm{~mm}$ of $\mathrm{Hg}$ & $9.1(3.16)$ & $8.9(4.4)$ & $8.3(1.7)$ \\
\hline Blood pressure $>160 / 100 \mathrm{~mm}$ of $\mathrm{Hg}$ in rural area & $9.4(2.73)$ & $8.4(5.04)$ & $7.6(2.41)$ \\
\hline Blood pressure $>160 / 100 \mathrm{~mm}$ of $\mathrm{Hg}$ in urban area & $9.8(4.18)$ & $9.8(3.58)$ & $8.98(1.29)$ \\
\hline \multicolumn{4}{|l|}{ Analysis of blood pressure (Very High) } \\
\hline Blood pressure $>180 / 110 \mathrm{~mm}$ of $\mathrm{Hg}$ & $3.5(1.7)$ & $3.6(2.24)$ & $3.05(0.60)$ \\
\hline Blood pressure $>180 / 110 \mathrm{~mm}$ of $\mathrm{Hg}$ in rural area & $3.52(1.52)$ & $3.54(2.51)$ & $2.81(0.78)$ \\
\hline Blood pressure $>180 / 110 \mathrm{~mm}$ of $\mathrm{Hg}$ in urban area & $4.17(2.81)$ & $3.8(1.77)$ & $3.35(0.55)$ \\
\hline
\end{tabular}

Source: DLHS - 4 (Ministry of health and family welfare 2012-2013). SD = Standard deviation

\begin{tabular}{|c|c|c|c|}
\hline Variables & $\begin{array}{c}\text { Marathwada } \\
\text { Mean \% ( } \pm \text { SD) }\end{array}$ & $\begin{array}{c}\text { RoM } \\
\text { Mean \% (SD) }\end{array}$ & $\begin{array}{c}\text { Vidarbha } \\
\text { Mean \% ( } \pm \text { SD) }\end{array}$ \\
\hline \multicolumn{4}{|l|}{ Analysis of Blood Sugar level } \\
\hline Blood sugar $>140 \mathrm{mg} / \mathrm{dl}$ & $13.06(1.54)$ & $14.85(3.56)$ & $10.16(2.68)$ \\
\hline Blood sugar for rural area $>140 \mathrm{mg} / \mathrm{dl}$ & $11.88(1.78)$ & $13.57(3.21)$ & $9.15(3.11)$ \\
\hline Blood sugar $>160$ & $6.11(1.00)$ & $7.6(2.11)$ & $4.87(1.64)$ \\
\hline Blood sugar for rural area $>160$ & $5.25(1.11)$ & $6.51(1.96)$ & $3.86(1.54)$ \\
\hline \multicolumn{4}{|l|}{ Analysis of Blood Pressure } \\
\hline Blood pressure $>140 / 90$ & $21.56(3.11)$ & $25.45(3.55)$ & $24.28(4.08)$ \\
\hline Blood pressure $>140 / 90$ for rural area & $20.26(3.23)$ & $25.25(3.08)$ & $23.09(5.22)$ \\
\hline Blood pressure $>160 / 100$ & $7.03(1.25)$ & $9.51(1.86)$ & $8.9(3.99)$ \\
\hline Blood pressure $>160 / 100$ for rural area & $6.56(1.36)$ & $9.1(2.20)$ & $8.08(3.68)$ \\
\hline Blood pressure $>180 / 110$ for rural area & $2.63(0.75)$ & $3.37(0.62)$ & $3.5(1.52)$ \\
\hline Blood pressure $>180 / 110$ for rural area & $2.43(0.64)$ & $3.1(0.89)$ & $3.1(1.58)$ \\
\hline
\end{tabular}

Source: DLHS - 4 (Ministry of health and family welfare 2012-2013). SD = Standard deviation

$(13.17 \%)$ followed by southern state $(12.73 \%)$ and north-east (NE -region -10.21\%). Urban area seems to have higher percentages of population as compared to the rural area. Surprisingly, percentages of population for average sugar $(>140 \mathrm{~g})$ is more in North, but percentages of high sugar (blood sugar $>160 \mathrm{mg}$ ) were found in Southern area than Northern and NE-region indicating high-risk group prone to diabetes. This means South Indian people are at more risk of developing future diabetes and cardiac diseases as compared to other region people. Sikkim from NE-region showed very high burden of population having blood sugar more than $160 \mathrm{mg} / \mathrm{dl}$. NPCDC data and various studies in North and NE-region showed the prevalence of diabetes around 10\% associated with behavior practices, particularly high calorie diet intake with edible oil, rice, and fish, while Kerala from Southern region emerged as outlier (having around $25 \%$ of population's blood sugar more than $160 \mathrm{mg} / \mathrm{dl}$ in rural and urban area as well).

\section{Blood pressure analysis of India}

Percentages of population in all three categories (average BP $>140 / 90 \mathrm{mmHg}$, moderate $\mathrm{BP}>160 / 100 \mathrm{mmHg}$, and very high BP $>180 / 110 \mathrm{mmHg}$ ) are high in Northern region, followed by NE-region and Southern region [Table 3], indicating future high-risk population for the developing heart diseases, vascular diseases such as peripheral vascular diseases and nervous system disease. Kerala exceeds the other states in India for the number of people with high BP more than 140/90 $\mathrm{mmHg}$. Around 35\% of population of Kerala showing increased BP more than 140/90 $\mathrm{mm}$ of $\mathrm{Hg}$ [Figure 2] indicating alarming signals for developing future heart disease or risk of deaths associated with hypertension. Need of an hour would be spreading awareness for healthy diet practices to cut down the future prevalence of heart and other diseases. Urban areas in all three regions showed the high percentages of high BP 


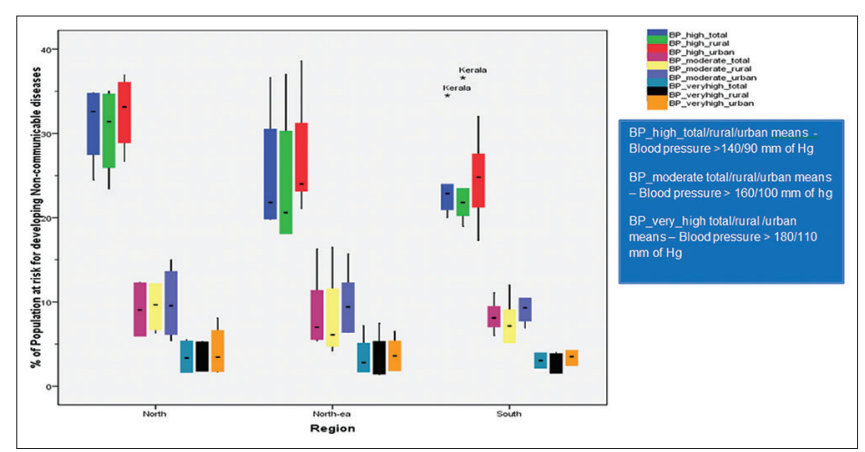

Figure 2: Region-wise state level distribution of Blood pressure of India

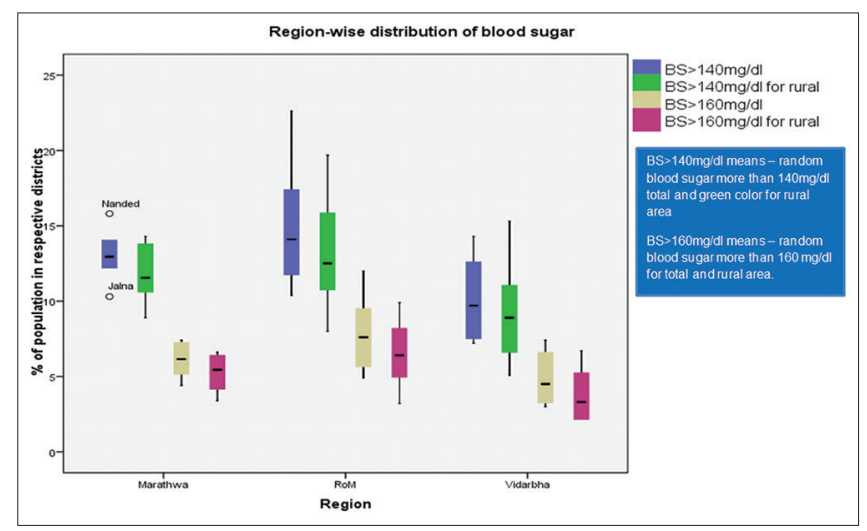

Figure 3: District level region-wise distribution of Blood Sugar of Maharashtra

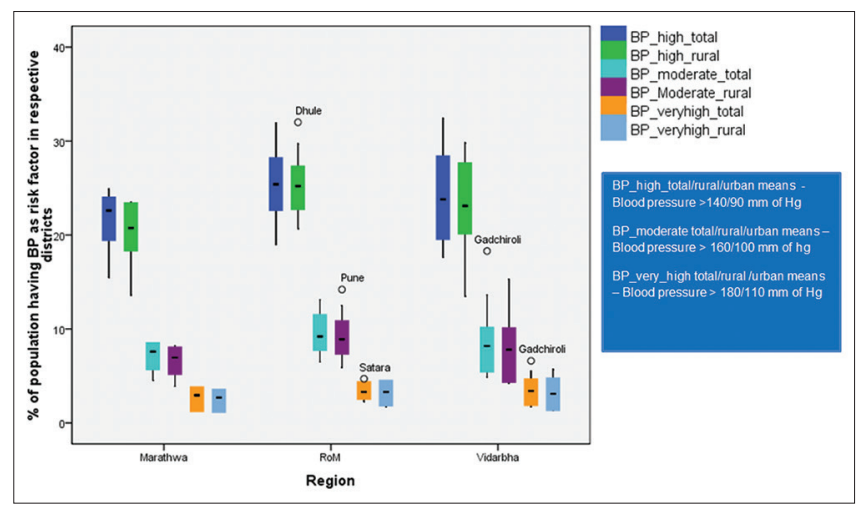

Figure 4: District level region-wise distribution of Blood pressure of Maharashtra

$>180 / 110 \mathrm{mmHg}$ as compared to the rural area. Urban area of all three regions showing 3-4\% of population's BP more than 180/110 mm of $\mathrm{Hg}$ [Table 3] indicating dangerous future risk of deaths associated with high BP such as stroke (brain disease) and myocardial infarction (M.I) (heart disease).

\section{Blood sugar analysis of Maharashtra}

In RoM, $14.85 \%$ of the population were affected by slight increase in average blood sugar $(140 \mathrm{mg} / \mathrm{dl})$ followed by Marathwada $(13.06 \%)$ and Vidarbha (10.16\%). Blood sugar $>160 \mathrm{mg} / \mathrm{dl}$ was also found more in RoM as compared to Marathwada and Vidarbha [Table 4].
Nanded district emerged as an outlier (showing more than 15\% of population having blood sugar more than $140 \mathrm{mg} / \mathrm{dl}$ ) [Figure 3]. Jalna showed that around $10 \%$ of population are having blood sugar around $140 \mathrm{mg} / \mathrm{dl}$. From Figure 3, we can say that, in rural area of Marathwada region, half of the rural districts more than 13-14\% of population showed blood sugar more than $140 \mathrm{mg} / \mathrm{dl}$, whereas more than half of the district's $6-10 \%$ of population showed blood sugar more than $160 \mathrm{mg} / \mathrm{dl}$. In case of RoM, more than half of the district's $12-16 \%$ of population showed blood sugar more than $140 \mathrm{mg} / \mathrm{dl}$. Percentage of RoM population exceeds Vidarbha and Marathwada for showing high blood sugar more than $160 \mathrm{mg} / \mathrm{dl}$ [Figure 3]. More than half of the district's $5-10 \%$ of population shows blood sugar more than $160 \mathrm{mg} / \mathrm{dl}$. In case of Vidarbha, more than half of the district's $4-7 \%$ of population showed blood sugar more than $160 \mathrm{mg} / \mathrm{dl}$. While in case of Marathwada, more than half of the district's $5-7 \%$ of population showed blood sugar more than $160 \mathrm{mg} / \mathrm{dl}$. Eventually, the RoM's major proportions of population are on high risk of developing future risk of diabetes in all three categories.

\section{Analysis of blood pressure}

Percentages of population in all three categories, say average (BP $>140 / 90) \mathrm{mmHg}$, moderate (BP >160/100) $\mathrm{mmHg}$, and very high (BP $>180 / 110 \mathrm{mmHg}$ ) are high in RoM region, followed by Vidarbha and then Marathwada regions [Table 4, Figure 4]. In RoM, more than half of the district's $22-26 \%$ of population showed BP more than 140/90 mmHg. Dhule emerged as outlier showing more than $30 \%$ of population's BP more than $140 / 90 \mathrm{mmHg}$. In Vidarbha, more than half of the district's $18-28 \%$ of population showed BP more than 140/90 mmHg. In most of the district's in Marathwada, 18-24\% of population showed the BP more than $140 / 90 \mathrm{mmHg}$. Percentages of population with moderate to high $\mathrm{BP}(160 / 100 \mathrm{mmHg})$ and very high BP $(180 / 120 \mathrm{mmHg})$ are more in RoM than Vidarbha and Marathwada. Pune and Satara emerged as outlier in moderate and high BP whereas in case of Vidarbha, it is the Gadchiroli district's 28\% population showed moderate to high BP whereas $7 \%$ population showed very high BP indicating need of special focus in tribal area. Vidarbha region's population is more dispersed as compared to RoM and found high risk in all three categories. Pune emerged as outlier for moderate BP $(160 / 100 \mathrm{mmgh})$ in a study which predicts the future risk of deaths associated with increased BP such as stroke and M.I.

\section{DISCUSSION}

NCDs contribute to around 5.87 million deaths that account for $60 \%$ of all deaths in India. India shares more than $66 \%$ of total deaths attributed to NCDs in South-East Asian region.

Prevalence of diabetes varies country-to-country, within continent, state-to-state, and also region-to-region within state. From various studies done in India, Northern region emerged as a high risk area for diabetes as compared to the other regions, here in DLHS-4 
survey, North region again emerged with more percentages of people with high blood sugar and BP followed by South region and NE. ${ }^{[4]}$ Possible cause of high risk for the risk factors may be attributed to the recent development of this region and suddenly changed life style behavior among Northern people, ${ }^{[5]}$ indicating the need of more specific intervention of life style modification in Northern part as compared to Southern part. In Southern region, the high burden of blood sugar and BP attributed to the abdominal obesity, urban residency, and physical inactivity. ${ }^{[6]}$ These disparities in the prevalence of risk factors may be attributed to reporting, optimum work of specific health government or social cultural and demographic factors of particular region.

Within the state, burden of prevalence varies region-to-region, if you look at the Maharashtra state, RoM emerged as high risk for increased blood sugar followed by Vidarbha and then Marathwad, whereas Vidarbha's most of percentages of population showed high risk for increased BP as compared to other part. High blood sugar and high BP of Vidarbha region may be attributed to the geographical location, tribal, rural region. Predisposing behavioral practices such as tobacco consumption, liquor consumption are common among male while physical inactivity, obesity are common among the females and low intake vegetables and fruit intake are common among both genders may attributed to the high prevalence of risk factors in this region. ${ }^{[7]}$ In the present study, from the secondary data analysis, it is shown that the future burden of NCDs, particularly of diabetes and hypertension varies region-to-region and even within region district-to-district indicating need of region wise/hotspot approach for health education and intervention depending upon their cultural, social practices.

\section{A call for "Health promotion" once again}

India's current approach for intervention is more in terms of screening blood sugar testing and putting the same patients on anti-glycemic agents, indeed for cutting down the burden of Type-2 diabetes, there is intervention for the prevention of risk factors such as sugar intake and salt intake which needs a different approach. Starting "World Yoga Day" on 21 ${ }^{\text {st }}$ June is one step for addressing the issue of physical inactivity. Indeed for addressing other issues such as healthy eating practices, reduction of alcohol, and complete ban on tobacco consumption, separate health education program is needed for effective intervention of NCDs.

Instead of concentrating on disease or prevalence indicators, one should focus on risk factors. Policies for the NCDs should be more toward the health promotion rather than disease cure rate and identification of prevalence rates. NCDs disease need infrastructure at individual and community level, certainly NCDs need intervention more earlier than what we are giving in disease. State or nation should focus more on health promotion rather than cure rate in NCDs. Future burden of NCDs (diabetes, hypertension, and hypercholesterolemia) would be attributed to the present steps toward the health promotion. Cases of impaired glucose tolerance, prehypertension, gestational diabetes, screening for high risk individuals, etc., need to identify on time and halted on proper time to reduce the future burden of mortality and morbidity attributed to NCDs.

People of India are very diverse in nature; in terms of their behavior, diet practices, cultural practices, belief of health and health-regarding practices, and their health-seeking behavior indicating need to have targeted approach for the health promotion. Regional difference of prevalence of risk factors such as blood sugar and BP varies region-to-region and even in one region, district-to-district which is attributed to their ethnicity and their unique cultural practices. For the prevention of morbidity and mortality attributed to diabetes and hypertension, there is a need of understanding or situational assessment of respective region and creating health promotion based on their cultural norms and values. Eventually, the above DLHS-4 survey and above analysis showed that there is an upcoming burden of risk factors for diabetes and hypertension, indicating a need of screening not only for diabetes and hypertension, but also screening and intervention of "risk factors" such as Obesity, increased cholesterol, and metabolic syndrome should be taken care. Without health promotion for healthy practices, intervention of diabetes and hypertension has no use and would be like water off duck's back.

\section{Acknowledgment}

The author would like to thank the International Institute of Population Sciences, for providing available data on website.

\section{Financial support and sponsorship}

Nil.

\section{Conflicts of interest}

There are no conflicts of interest.

\section{REFERENCES}

1. Available from: http://www.who.int/mediacentre/news/releases/2012/ world_health_statistics_20120516/en/. [Last accessed on 2015 Aug 20].

2. WHO Report on Global Health Risk; 2009.

3. WHO Report on Burden of NCDs and Their Risk Factors in India; 2014-15.

4. Mohan V, Pradeep R. Epidemiology of diabetes in different regions of India. Health Adm 2009;12:1-18.

5. Khongsdier R. Increasing urbanization in tribal states of Northeast India; implication for the prevalence of chronic diseases. Tribes and Tribals, In: Bose K, editor. Health and nutritional problems of indigenous population. New Delhi: Kamal Raj Enterprises; 2008. p. 25-33.

6. Mohan V, Mathur P, Deepa R, Deepa M, Shukla DK, Menon GR, et al. Urban rural differences in prevalence of self-reported diabetes in India The WHO-ICMR Indian NCD risk factor surveillance. Diabetes Res Clin Pract 2008;80:159-68.

7. Bhardwaj S, Shewte M, Bhatkule P, Khadse J. Prevalence of risk factors for non-communicable disease in a rural area of Nagpur district, Maharashtra A WHO step wise approach. Int J Biol Med Res 2012;1:1413-8. 